\title{
Bismuth subsalicylate reduces peptic injury of the oesophagus in rabbits
}

\author{
H P Tay, R C Chaparala, J W Harmon, J Huesken, N Saini, F Z Hakki, E J Schweitzer
}

\begin{abstract}
Bismuth subsalicylate was tested in an in vivo perfused rabbit model of oesophagitis for its ability to prevent the mucosal injury caused by pepsin. Treatment efficacy was assessed under both a treatment-before-injury protocol and a treatment-after-injury protocol. Oesophageal mucosal barrier function was evaluated by measuring flux rates of $\mathrm{H}^{+}, \mathrm{K}^{+}$, and glucose. The degree of oesophagitis was determined by gross and microscopic examination of the mucosa by several independent observers. Results showed that under both treatment protocols, bismuth subsalicylate significantly reduced the pepsin induced disruption of the mucosal barrier, as well as the morphologic changes. Bismuth subsalicylate when given after exposure to pepsin was also found to protect against the morphologic injury in a dose dependent manner. Experiments in vitro suggested that bismuth subsalicylate inhibits the proteolytic action of pepsin by interacting with pepsin, rather than with the pepsin substrate. We conclude that bismuth subsalicylate can protect the oesophageal mucosa against peptic injury, probably through inactivation of pepsin.
\end{abstract}

The oesophageal mucosal injury found in patients with reflux oesophagitis occurs as a result of abnormal exposure of the mucosa to the corrosive gastric contents. We have used an in vivo perfused rabbit model of oesophagitis to elucidate the mechanisms of oesophageal mucosal injury ${ }^{1-5}$ and to test agents which might be useful in the prevention or treatment of such injury ${ }^{6}$

The present study was designed to test the efficacy of bismuth subsalicylate in preventing experimental oesophagitis. Bismuth subsalicylate has been used for many years as an overthe-counter drug for the relief of heartburn, which is often associated with oesophagitis. Bismuth compounds have been shown to reduce experimental gastric mucosal injury in the rat, ${ }^{78}$ and they have been used successfully to treat peptic ulcer disease in man..$^{90}$ Ulcer healing with bismuth compounds has been shown to be similar to cimetidine, ${ }^{11-13}$ even though it lacks a significant acid neutralising capacity. Because the mucosa of the oesophagus and stomach are both exposed to the same caustic gastric contents, we investigated whether bismuth is efficacious against mucosal injury of the oesophagus.

Some of the potentially injurious components of the oesophageal refluxate fluid include hydrochloric acid $(\mathrm{HCl})$, proteolytic enzymes such as pepsin, and the bile acids. ${ }^{3}$ In experimental models of oesophagitis $\mathrm{HCl}$ inflicts little injury to the intact oesophageal epithelium, except at very high concentrations and after prolonged periods of exposure..$^{16}$ The bile acids typically increase the oesophageal mucosal permeability, but cause only a relatively modest degree of accompanying morphologic change. ${ }^{+6}$ In contrast, pepsin not only causes a significant increase in the permeability of the oesophageal mucosa, but also causes a frankly haemorrhagic, severe morphologic injury. ${ }^{36}$ The present study was therefore carried out with pepsin as the injurious agent, as it appears to be the most damaging of the components of an acidic gastroesophageal refluxate fluid.

We performed in vivo experiments to determine whether bismuth subsalicylate had protective effects against the pepsin induced oesophageal injury. Bismuth subsalicylate was tested in a treatment-before-injury and a treatment-after-injury protocol. After bismuth was found to be protective in vivo, the antipepsin activity of bismuth subsalicylate was tested in vitro to attempt to clarify its mechanism of action.

\section{Methods}

\section{IN VIVO EXPERIMENTS}

\section{Oesophageal perfusion}

An in vivo perfused rabbit model of oesophagitis, adapted from Chung ${ }^{12}$ was used as described. ${ }^{136}$ In brief, New Zealand white rabbits weighing 3-5 kg were lightly anaesthetised with an intramuscular injection of ketamine/xylazine. The oesophagus was cannulated in the neck at the pharyngoesophageal junction and in the abdomen at the gastroesophageal junction with plastic tubing (id $0.317 \mathrm{~mm}$ ). The oesophagus was then perfused with $45 \mathrm{ml}$ of various test solutions at $10 \mathrm{ml} / \mathrm{min}$ using a peristalic pump (Harvard Apparatus Co, Millis, MA) and a recirculating system. The perfusate solution was stirred mechanically (Haake, Berlin, Germany), and a thermoregulator (Haake) kept the temperature of the perfusate at $37^{\circ} \mathrm{C}$. A pH stat/ autoburette system (Radiometer, Cophenhagen, Denmark) containing $0.4 \mathrm{~N} \mathrm{HCl}$ constantly maintained the $\mathrm{pH}$ of the perfusate at 2 .

Each experiment consisted of a 30 minute 'exposure period' in which the perfusate solution contained pepsin at $\mathrm{pH} 2$. This was followed by a 40 minute 'flux period' in which the perfusate solution contained no pepsin, but was used for measuring transmucosal flux rates of $\mathrm{H}^{+}, \mathrm{K}^{+}$, and glucose. In the treatment-before-injury protocol, for 10 minutes before the initiation of the 30 minute exposure period, the oesophagus 
was perfused with either saline $145 \mathrm{mmol} / \mathrm{l}$ (control group) or saline plus bismuth subsalicylate (The Procter and Gamble Co, Cincinnati, $\mathrm{OH}) 30 \mathrm{mg} / \mathrm{ml}$ (study group), bopth at $\mathrm{pH} 2$. At the start of the exposure period, porcine pepsin (Sigma Chemical Co, St Louis, Missouri) was added to the perfusate of both the control and study groups to obtain a final perfusate concentration of $1 \mathrm{mg} / \mathrm{ml}$. The $\mathrm{pH}$ of the perfusate was maintained at 2.0 with $\mathrm{HCl}$. At the end of this exposure period, the perfusate was discarded and the entire system, including the oesophagus, was irrigated with $100 \mathrm{ml}$ isotonic saline in preparation for the subsequent flux period.

The exposure period in the treatment-afterinjury protocol was similar to that in the treatment-before-injury protocol, except that the bismuth subsalicylate was added after an initial oesophageal exposure to pepsin. The 30 minute exposure period of both the control and study groups began with perfusion of the oesophagus with a solution containing $1 \mathrm{mg} / \mathrm{ml}$ of porcine pepsin at $\mathrm{pH} 2$. Ten minutes after the initiation of the exposure period, an amount of bismuth subsalicylate was added to the perfusate solution of the study groups to obtain a concentration of either $15 \mathrm{mg} / \mathrm{ml}, 30 \mathrm{mg} / \mathrm{ml}$, or $60 \mathrm{mg} /$ $\mathrm{ml}$ of bismuth subsalicylate. Concomitantly, a quantity of pepsin and $\mathrm{HCl}$ was added to the perfusate to maintain the pepsin concentration at $1 \mathrm{mg} / \mathrm{ml}$ and the $\mathrm{pH}$ at 2 . At the end of the exposure period, the perfusate was discarded and preparation was made for the flux period, as in the treatment-before-injury protocol.

The methods used during the flux period were identical for both the treatment-before-injury and the treatment-after-injury protocols. The flux solution contained $1.5 \mathrm{~g} / 1$ polyethylene glycol (PEG, Fisher Scientific Co, Fair Lawn, NJ) $100 \mathrm{mCi} / 1{ }^{3} \mathrm{H}$-PEG (New England Nuclear, Boston, Mass), and $10 \mathrm{mM} \mathrm{HCl}$ at $\mathrm{pH} 2$. The osmolality was brought to $280 \mathrm{mosmol} / \mathrm{l}$ with mannitol. A $4 \mathrm{ml}$ aliquot of the flux solution was taken from the reservoir at the beginning and end of the $\mathbf{4 0}$ minutes flux period for later analyses of $\mathrm{K}^{+}$and glucose. $\mathrm{A} \mathrm{pH}$ of 2 was constantly maintained in the perfusate solution with the $\mathrm{pH}$ stat/autoburette apparatus. After completion of the flux period, the animal was killed with an intracardiac bolus of pentobarbital and the oesophagus was excised.

\section{Calculation of fluxes}

Oesophageal mucosal permeability to ions and small molecules was determined by calculating $\mathrm{H}^{+}, \mathrm{K}^{+}$, and glucose flux rates. Hydrogen ion flux out of the lumen was given by the amount of $\mathrm{HCl}$ delivered by the $\mathrm{pH}$ stat/autoburette apparatus to maintain the $\mathrm{pH}$ of the solution at 2 . Concentrations of $\mathrm{K}^{+}$were assayed by ion selective electrode potentials (Beckman System E4A, Beckman Instruments, Fullerton, CA), and concentrations of glucose were assayed by the hexokinase reaction (Centrifichem System 500, Union Carbide Corp, Rye, NY). Fluxes were calculated using the following formula:

$$
\text { Net flux }=\left(C_{F}-C_{I}\right) \times V_{I}
$$

where $V_{I}$ is the initial volume of the perfusate at the beginning of the flux period, $C_{I}$ is the initial concentration of $\mathrm{K}^{+}$or glucose in the perfusate solution, and $C_{F}$ is the final concentration. ${ }^{3} \mathrm{H}$-PEG was used as an impermeable volume marker during the initial experiments. It was not used in the later experiments because it was found to be unnecessary, as have others who have used this animal model have reported. ${ }^{1+}$ Polyethylene glycol was deemed unnecessary when it was found in the initial experiments that the volume and PEG recovery rates were between 96-99\%, and the volume flux was relatively low (less than $0.5 \mathrm{ml}$ per experiment).

\section{Determination of oesophagitis index}

Immediately after removal, the oesophagus was fixed in $10 \%$ formalin. A photograph of the fixed specimen was taken for later grading of the degree of gross morphologic injury. Histologic slides were prepared from sections taken from the proximal, central, and distal portions of the esophagus and stained with haematoxylin and eosin. Photographs and slides of all specimens were scored for the severity of oesophagitis by several observers unaware of the treatments given, using a system previously described. ${ }^{36}$ In brief, the gross oesophagitis index was determined by the following criteria: $1=$ normal appearance; $2=$ erythema or other abnormal appearance, but no haemorrhage; $3=$ nonconfluent mucosal haemorrhage; $4=$ confluent intramural haemorrhages (Fig 1). The microscopic oesophagitis index was scored by these
Figure 1: Grades of gross oesophagitis. Numbers correspond to the gross oesophagitis index (GOI).

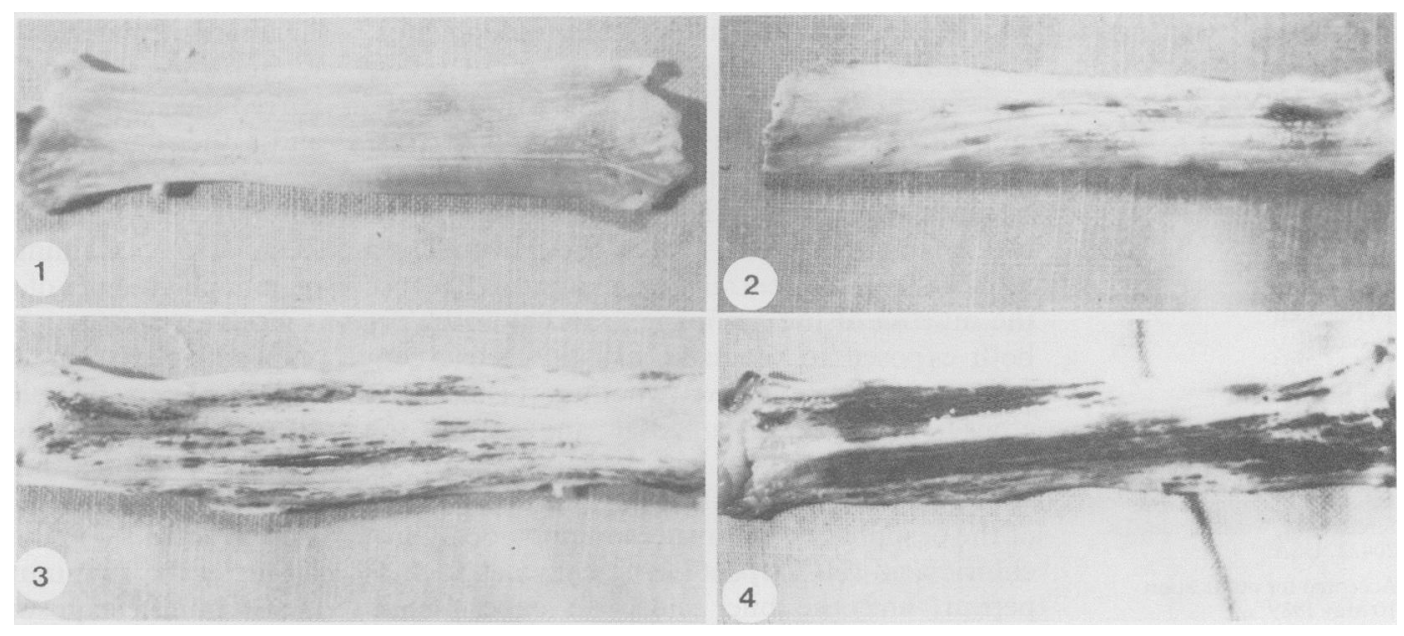


Figure 2: Grades of microscopic oesophagitis. Numbers correspond to the microscopic oesophagitis index $(M O I)$.
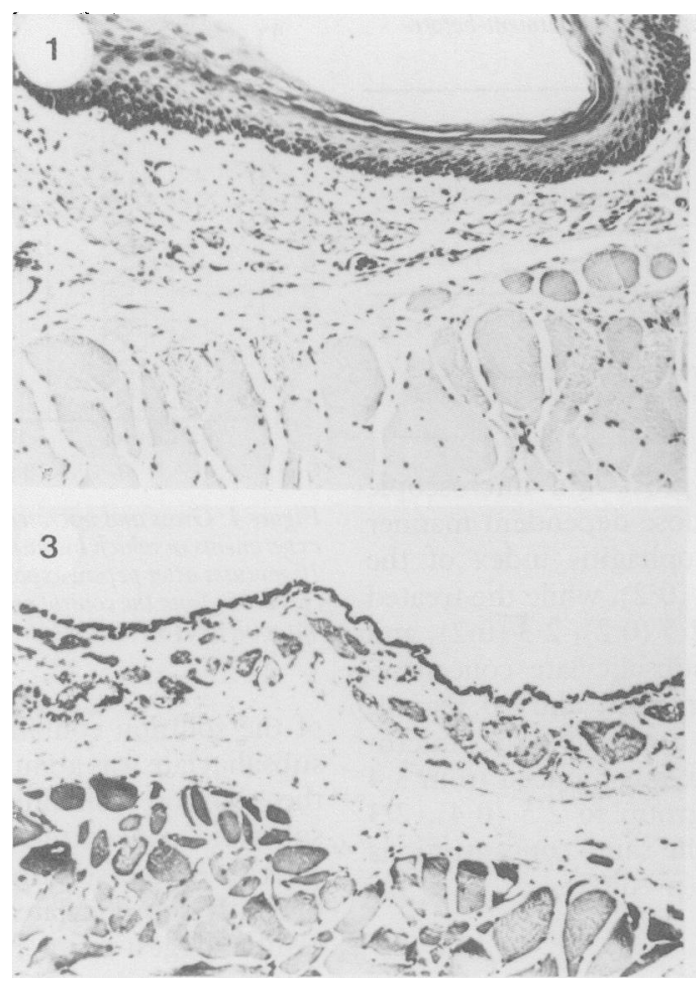

criteria: 1 =normal oesophagus; 2 =submucosal oedema or separation of epithelial layers; $3=$ focal areas of intramural haemorrhage or partial epithelial loss; $4=$ large areas of haemorrhage or complete epithelial desquamation (Fig 2).

\section{In vitro experiments}

A series of in vitro experiments were performed to determine whether bismuth subsalicylate could inhibit the proteolytic action of pepsin on haemoglobin, and if so, whether this inhibition was caused by the interaction of bismuth subsalicylate with pepsin or its substrate. The biochemical principle underlying this experiment was that if an enzyme inhibitor acts by binding to the substrate molecule, then the inhibition observed at a low substrate concentration can be reduced by providing more substrate to the reaction. Alternatively, if the inhibition is caused by the inhibitor binding to the enzyme, then the inhibition will not be reduced by increasing the concentration of substrate. ${ }^{17}$ In the experiment, $50 \mathrm{mg} / \mathrm{ml}$ pepsin was dissolved in one of the following solutions: (a) $\mathrm{HCl}$ at $\mathrm{pH} 2$, or (b) $\mathrm{HCl}$ plus $30 \mathrm{mg} / \mathrm{ml}$ bismuth subsalicylate at $\mathrm{pH}$ 2. The peptic activity of these solutions was then assayed by spectrophotometrically measuring the amount of tyrosine released from $2.5 \mathrm{ml}$ of $1,2,3$, or $4 \mathrm{~g} \%$ solutions of bovine haemoglobin substrate. ${ }^{18}$

\section{Statistical analysis}

Each experimental group contained between five and nine animals. All results are expressed as the mean \pm one standard error of the mean (SE). The differences between means of groups of continuous data $\left(\mathrm{H}^{+}, \mathrm{K}^{+}\right.$, and glucose flux rates) were assessed for statistical significance $(\mathrm{p}<0.05)$ using the Student's unpaired $t$ test. Non-parametric data (gross and microscopic

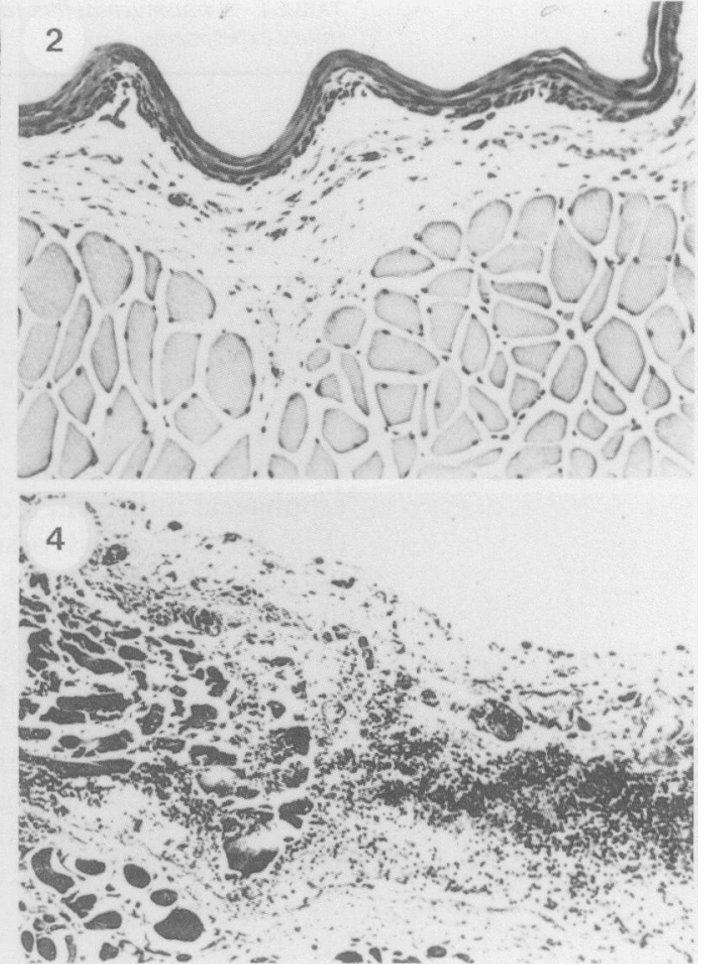

oesophagitis grades) were compared for significant differences $(p<0.05)$ with the MannWhitney test.

\section{Results}

\section{IN VIVO EXPERIMENTS}

\section{Treatment-before-injury protocol}

When administered before exposure of the oesophageal mucosa to pepsin, bismuth subsalicylate reduced both the permeability changes and the morphologic injury caused by pepsin. As shown in Table I, significantly lower transmucosal flux rates of $\mathrm{H}^{+}, \mathrm{K}^{+}$, and glucose occurred in the group treated with bismuth subsalicylate than in the untreated group $(p<0.05)$. Treatment with bismuth subsalicylate before pepsin exposure also significantly reduced the morphologic injury, as reflected by both the gross and microscopic oesophagitis indices. The gross oesophagitis index of the untreated control group was $3 \cdot 2(0 \cdot 2)$, compared with the group treated with bismuth subsalicylate, which was graded as $2 \cdot 0$ $(0 \cdot 3)(p<0 \cdot 01$, Fig 3$)$. Similarly, the microscopic esophagitis index was reduced from $3 \cdot 1(0 \cdot 2)$ in the untreated group to $2 \cdot 1(0 \cdot 2)$ in the group treated with bismuth subsalicylate $(\mathrm{p}<0.001$, Fig 3).

Treatment-after-injury protocol

The efficacy of bismuth subsalicylate in reducing the oesophageal injury when administered after exposure to pepsin was similar to that observed when it was administered before the pepsin exposure. Flux rates of $\mathrm{H}^{+}, \mathrm{K}^{+}$, and glucose were significantly lower in the groups exposed to 15 $\mathrm{mg} / \mathrm{ml}, 30 \mathrm{mg} / \mathrm{ml}$, and $60 \mathrm{mg} / \mathrm{ml}$ of bismuth subsalicylate than those in the untreated control group ( $\mathrm{p}<0.05$, Table II). Bismuth subsalicylate 
TABLE I Transmucosal flux rates in the treatment-beforeinjury experiments

\begin{tabular}{llll}
\hline & Flux ratet & & \\
\cline { 2 - 4 } & $\begin{array}{l}H^{+} \\
(\mu \mathrm{mol} / 10 \mathrm{~min})\end{array}$ & $\begin{array}{l}K^{+} \\
(\mu \mathrm{mol} / 10 \mathrm{~min})\end{array}$ & $\begin{array}{l}\text { Glucose } \\
(\mu \mathrm{mol} / 10 \mathrm{~min})\end{array}$ \\
\hline No treatment & $53(6)$ & $7(1)$ & $5(1)$ \\
BSS treatment & $28(3)^{\star}$ & $3(1)^{\star}$ & $3(1)^{\star}$ \\
\hline
\end{tabular}

Results are expressed as mean (SE). Bismuth subsalicylate $30 \mathrm{mg} / \mathrm{ml}$.

$\star$ Significantly different from no treatment group, $\mathrm{p}<0.05$; + Direction of flux: $\mathbf{H}^{+}=$out of lumen, $\mathbf{K}^{+}$, glucose $=$into lumen.

also reduced both the gross and microscopic esophageal indices in a dose dependent manner (Fig 4). The gross oesophagitis index of the untreated group was $3 \cdot 4(0 \cdot 2)$, while the treated groups were graded as $2 \cdot 5(0 \cdot 2), 2 \cdot 3(0 \cdot 2)$, and $1.8(0 \cdot 2)$ for bismuth subsalicylate concentrations of $15 \mathrm{mg} / \mathrm{ml}, 30 \mathrm{mg} / \mathrm{ml}$, and $60 \mathrm{mg} / \mathrm{ml}$, respectively $(p<0.05)$. Similarly, the microscopic oesophagitis index was reduced from $3 \cdot 4$ $(0.3)$ in the untreated group to $2 \cdot 5(0.4), 2 \cdot 3$ $(0.2)$, and $1.8(0.3)$ for the same concentrations of bismuth subsalicylate $(\mathrm{p}<0.05)$.

\section{In vitro experiments}

In vitro experiments were done to determine if bismuth subsalicylate interacted predominantly with pepsin or its substrate. Peptic activity of acidic solutions containing either pepsin alone or pepsin plus bismuth subsalicylate was assayed in solutions containing haemoglobin substrate concentrations of $1,2,3$, and $4 \mathrm{~g} \%$. The results are shown in Figure 5 . When assayed in a $1 \%$ haemoglobin substrate solution, peptic activity

TABLE II Transmucosal flux rates in the treatment-afterinjury experiments

\begin{tabular}{llll}
\hline & Flux ratet & & \\
\cline { 2 - 4 } & $\begin{array}{l}H^{+} \\
(\mu \mathrm{mol} / 10 \mathrm{~min})\end{array}$ & $\begin{array}{l}K^{+} \\
(\mu \mathrm{mol} / 10 \mathrm{~min})\end{array}$ & $\begin{array}{l}\text { Glucose } \\
(\mu \mathrm{mol} / 10 \mathrm{~min})\end{array}$ \\
\hline No treatment & $61(5)$ & $7(1)$ & $8(2)$ \\
BSS $15 \mathrm{mg} / \mathrm{ml}$ & $49(5)^{\star}$ & $4(1)^{\star}$ & $4(1)^{\star}$ \\
BSS $30 \mathrm{mg} / \mathrm{ml}$ & $46(5)^{\star}$ & $3(1)^{\star}$ & $5(1)^{\star}$ \\
BSS $60 \mathrm{mg} / \mathrm{ml}$ & $43(7)^{\star}$ & $4(1)^{\star}$ & $5(1)^{\star}$ \\
\hline
\end{tabular}

Results are expressed as mean (SE). Bismuth subsalicylate. $\star$ Significantly different from no treatment group; $†$ Direction of flux: $\mathrm{H}^{+}=$out of lumen, $\mathrm{K}^{+}$, glucose $=$into lumen

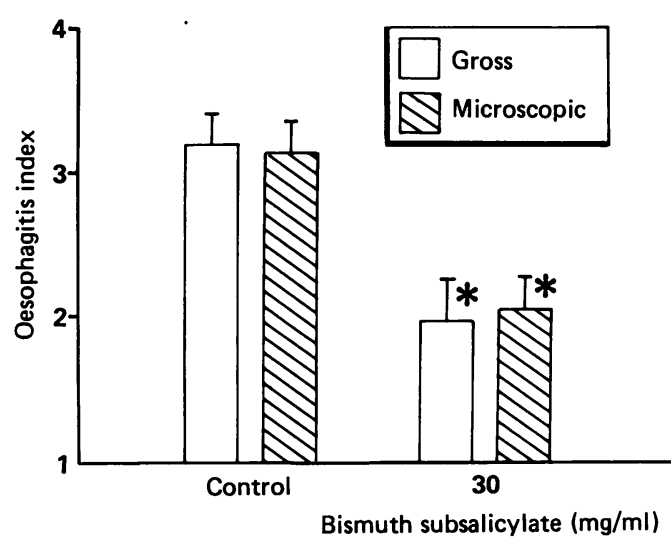

Figure 3: Gross and microscopic oesophagitis indices from experiments in which bismuth subsalicylate was administered before pepsin exposure. ${ }^{\star}=$ Significantly different $(p<0.01)$ from the control group, which was exposed to pepsin but with no bismuth subsalicylate treatment.

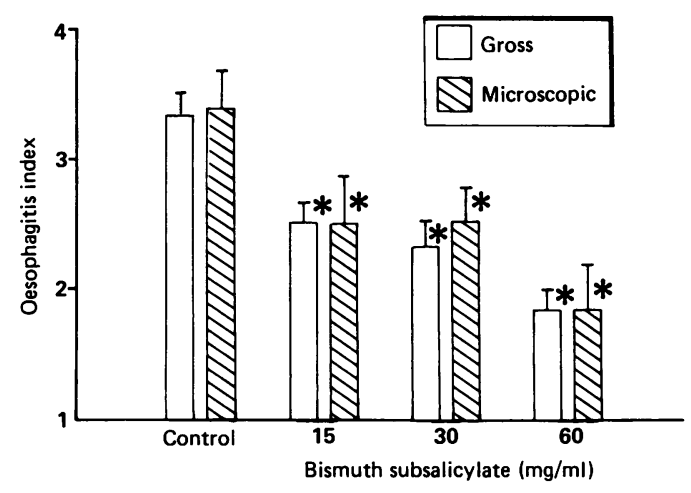

Figure 4: Gross and microscopic oesophagitis indices from experiments in which bismuth subsalicylate was administered 10 minutes after pepsin exposure. ${ }^{\star}=$ Significantly different $(p<0.05)$ from the control group, which was exposed to pepsin but with no BSS treatment.

of the solution containing pepsin plus bismuth subsalicylate was about half the peptic activity of the solution containing only pepsin. As the substrate concentration was increased, peptic activity of the solution containing pepsin plus bismuth subsalicylate did not increase. These results suggest an interaction of bismuth subsalicylate primarily with pepsin in vitro. It is also possible, however, that bismuth subsalicylate could exert some of its protective effect in vivo by binding to mucosal proteinaceous substrates for which it has a higher affinity than haemoglobin.

\section{Discussion}

The findings of this study show that bismuth subsalicylate can significantly reduce the severity of the oesophageal mucosal injury caused by pepsin. Administration of bismuth subsalicylate to rabbits, at concentrations similar to that in commercially available products (Pepto-Bismol, $17.5 \mathrm{mg} / \mathrm{ml}$ ), diminished the permeability changes and the morphologic injury induced by pepsin. This protection was observed whether bismuth subsalicylate was given before or after the oesophageal mucosa was exposed to pepsin. Additionally it was noted that, when given after exposure to pepsin, bismuth subsalicylate suppressed the pepsin mediated oesophageal morphologic injury in a dose dependent manner.

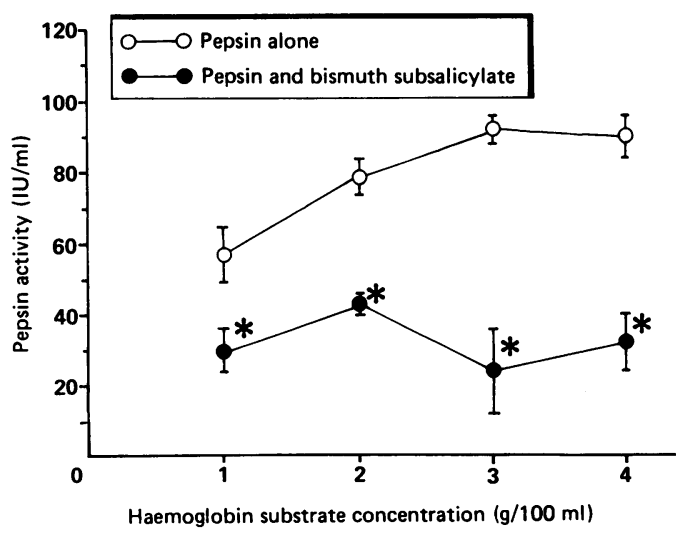

Figure 5: In vitro pepsin assay. Significantly lower pepsin activity was measured when bismuth subsalicylate was presen than when it was not $\left({ }^{\star}=p<0 \cdot 05\right)$. Bismuth subsalicylate apparently interacts directly with pepsin, rather than the substrate, because increasing the substrate concentration did not increase the peptic activity. 
There are several possible mechanisms by which this protection could occur. Bismuth compounds are known to complex with proteins. Bismuth subsalicylate could therefore interfere with the peptic digestion of the oesophageal mucosa by complexing with either pepsin or with the pepsin substrate protein in the mucosa. Our in vitro experiment would indicate that the former occurs and, indeed, pepsin inactivation by bismuth compounds has been described by others. ${ }^{12} 1920$

Alternatively, we could not rule out the possibility of a topical protective effect of bismuth subsalicylate by binding to the oesophageal mucosa in addition to the pepsin inactivation. It has been suggested that bismuth subsalicylate and other bismuth salts encourage gastric and duodenal ulcers to heal because of their ability to bind with various glycoproteins and mucopolysaccharides at the ulcer base. Bismuth compounds are thought to form a barrier over the base of an ulcer which protects it from the noxious luminal contents. ${ }^{21-25}$ When complexed with gastric mucus, bismuth has been shown to drastically retard the migration of hydrogen ions. ${ }^{26}$ These local effects have not yet been described in the oesophagus, but could have contributed to the protective effect observed in vitro in the present study. In a clinical setting administration of bismuth subsalicylate in a liquid form (Pepto Bismol, Proctor and Gamble), which could coat the oesophagus during swallowing, would be desirable to take advantage of any topical properties.

Bismuth is reported to exhibit other interesting properties which are pertinent to its potential applicability to the treatment of esophagitis. Colloidal bismuth was recently shown to suppress the activity and output of pepsin in patients with duodenal and gastric ulcers. ${ }^{27}$ This effect was still present 24 hours after the medication had been discontinued, suggesting the inhibition was sustained. ${ }^{28} \mathrm{~A}$ long lasting agent would be desirable in treating reflux oesophagitis, where protection is frequently needed during periods of nocturnal reflux. ${ }^{29}$ In addition, its activity against campylobacter like organisms may be beneficial, as these bacteria may contribute to the pathogenesis of oesophagitis in some cases. ${ }^{30}$

Current therapies for oesophagitis have traditionally included measures aimed at reducing reflux, either by increasing lower oesophageal sphincter tone or decreasing intra-abdominal pressure. Furthermore, the mainstay of therapy rests with reduction of gastric acidity. None of the existing therapies, however, are specifically directed at diminishing peptic injury of the mucosa, even though part of the efficacy of antacids may derive from a reduction of the refluxate pepsin activity through a $\mathrm{pH}$ rise. We recently found that the mucosal protective agent sucralfate was highly effective in preventing experimental peptic oesophagitis in the rabbit. ${ }^{6}$ This benefit was attributed to a topical protection when it was found that sucralfate did not inactivate pepsin. The present study suggests that, through direct inactivation of pepsin, bismuth subsalicylate could provide an added benefit to a clinical therapeutic regimen which might include a combination of agents acting to prevent mucosal injury by different mechanisms.

In conclusion, these studies indicate that bismuth subsalicylate can prevent the oesophageal mucosal injury caused by pepsin. Its effect derives, at least in part, from its capacity to interact with pepsin.

In conducting the research described in this report, the investigators adhered to the Guide for laboratory facilities and care as promulgated by the Committee on the Guide for Laboratory Animal Facilities and Care of the Institute of Laboratory Animal Rimal Facilities and Care of the Institute of Laboratory Anim Resources, National Academy of Sciences, National Research Council. This work was funded in part by Proctor and Gamble. The authors acknowledge the assistance of Barbara L Bass, Raj Lakshman, and his staff, and William Andrews.

1 Harmon JW, Johnson LF, Maydonovitch CL. Effect of acid and bile salts on the rabbit esophageal mucosa. Dig Dis $S$ and bile salts on

2 Lillemoe KD, Johnson LF, Harmon JW. Alkaline esophagitis: a comparison of the ability of components of gastroduodenal contents to injure the rabbit esophagus. Gastroenterology 1983; 85: 621-8.

3 Lillemoe KD, Johnson LF, Harmon JW. Role of the components of the gastroduodenal contents in experimental acid esophagitis. Surgery 1982; 92: 276-84.

4 Schweitzer EJ, Bass BL, Batzri S, Harmon JW. Bile acid accumulation by rabbit esophageal mucosa. Dig Dis $S c i$ 1986; 31: 1105-13.

5 Schweitzer EJ, Bass BL, Batzri S, Young PM, Huesken J, Harmon JW. Lipid solubilization during bile salt-induced esophageal mucosal barrier disruption in the rabbit. $\mathcal{f} L a b$ Clin Med 1987; 110: 172-9.

6 Schweitzer EJ, Bass BL, Johnson LF. Sucralfate prevents experimental peptic esophagitis in rabbits. Gastroenterolog 1985; 88: 611-9.

7 Goldenberg MM, Honkomp LJ, Burrous SE, et al. Protective effect of Pepto-Bismol Liquid on the gastric mucosa of rats. Gastroenterology 1975; 69: 636-40.

8 Wilson TR. Effect of tripotassium citrato bismuthate (TDB) on the healing of experimental gastric ulcers in rats. Postgrad Med F 1975; 51 (suppl 5): 22-5.

9 Eberhardt R, Kasper G, Dettmer A, Hochter W, Hagena D. Effect of oral bismuth subsalicylate on campylobacter pyloridis and on duodenal ulcer. Gastroenterology 1987; 92: pyloridis.

10 Lee FI, Samloff IM, Hardman M. Comparison of tripotassium dicitrato bismuthate tablets with ranitidine in healing and relapse of duodenal ulcers. Lancet 1984; i: 1299 302.

11 Martin DF, May SJ, Tweedle DEF, Hollanders D Ravenscroft MM, Miller JP. Difference in relapse rates of duodenal ulcer after healing with cimetidine or tripotassium dicitrato bismuthate. Lancet $1981 ;$ i: $7-10$.

12 Tytgat GNJ, Hameeteman W, Van Olffen GH. Sucralfate, bismuth compounds, substituted benzimidazoles, trimipramine and pirenzepine in the short- and long-term treatment of duodenal ulcer. Clin Gastroenterol 1984; 13: 543-68.

13 Dekker W, Reisma K. Double-blind controlled trial with colloidal bismuth subcitrate in the treatment of symptomatic
duodenal ulcers, with special references to blood and urine duodenal ulcers, with special refere
levels. Ann Clin Res 1979; 11: 94-7.

14 Chung RSK, Magri J, DenBesten L. Hydrogen ion transport in the rabbit esophagus. Am $\mathcal{F}$ Physiol 1975; 299: 496-500.

15 Salo J, Kivilaakso E. Role of luminal $\mathrm{H}^{+}$in the pathogenesis of experimental esophagitis. Surgery 1983; 92: 61-8.

16 Orlando RC, Nabila A, Turjman NA. Mucosal protection by sucralfate and its components in acid-exposed rabbi esophagus. Gastroenterology 1987; 93: 352-61.

17 Bergmeyer HU, ed. Methods of enzymatic analysis, vol 2. Deerfield Beach, Florida: Verlag Chemie International, 1981: 1046-57.

18 Decker LA. Worthington enzyme manual. Freehold, NJ: Worthington Biochemical Corporation, 1977.

19 Bateson PR. A comparative in vitro evaluation of a new bismuth salt, bismuth aluminate. $\mathcal{F}$ Pharm Pharmacol 1958; 10: 123-31.

20 Bateson PR. The effect of bismuth carbonate and other antacids on the activity of pepsin. Medicine $1954 ; 8: 370-4$

$21 \mathrm{Koo} \mathrm{J}$, Ho J, Lam SK. Selective coating of gastric ulcer by tripotassium dicitratobismuthate in the rat. Gastroenterology 1982; 82: 864-70

22 Soutar RL, Coghill SB. Interaction of tripotassium dicitrato bismuthate with macrophages in the rat and in vitro. Gastroenterology 1986; 91: 84-93.

23 Brogden RN, Pinder RM, Sawyer PR. Trioptassium dicitratobismuthate: a report of its pharmacological properties and bismuthate: a report of its pharmacological properties and

24 Wieriks J, Hespe W, Jaitly D. Pharmacological properties of colloidal bismuth subcitrate. Scand $\mathcal{F}$ Gastroenterol 1986; 17 (suppl 80): 11-6.

25 Wilson TR. The pharmacology of tripotassium dicitratobismuthate (TDB). Postgrad Med f 1975; 51 (suppl 5): 18-21

26 Lee SP. A potential mechanism of action of colloidal bismuth subcitrate: diffusion barrier to hydrochloric acid. Scand $\mathcal{F}$ Gastroenterol 1982; 17 (suppl 80): 17-21. 
27 Baron JH, Barr J, Batten J, Sidebotham R, Spencer J. Acid, pepsin, and mucus secretion in patients with gastric and duodenal ulcer before and after colloidal bismuth subcitrate (De-Nol). Gut 1986; 27: 486-90.

28 Colin-Jones DG. There is more to healing ulcers than suppressing acid. Gut 1986; 27: 475-80.
29 DeMeester TR, Johnson LF, Guy JJ, Toscano MS, Hall AW, Skinner DB. Patterns of gastroesophageal reflux in health and disease. Ann Surg 1976; 184: 459-70. 30 Borkent MV, Beker JA. Treatment of ulcerative reflux tion with cimetidine. Gut 1988; 29: 385-9. 